\title{
Femtosecond time-resolved photodissociation dynamics of methyl halide molecules on ultrathin gold films
}

\author{
Mihai E. Vaida, Robert Tchitnga and Thorsten M. Bernhardt ${ }^{*}$
}

\section{Full Research Paper}

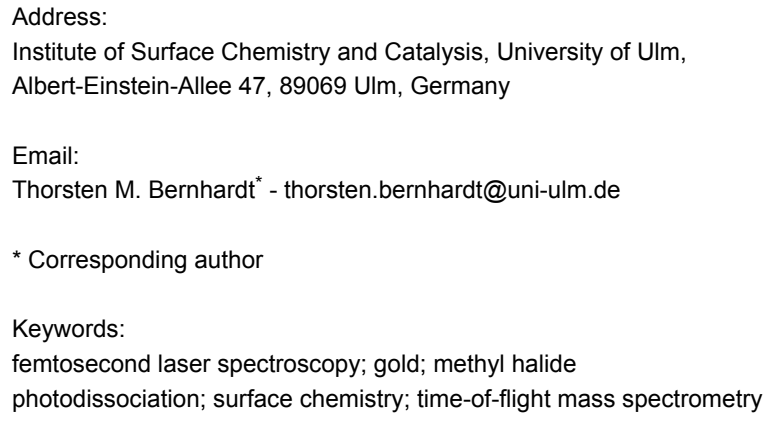

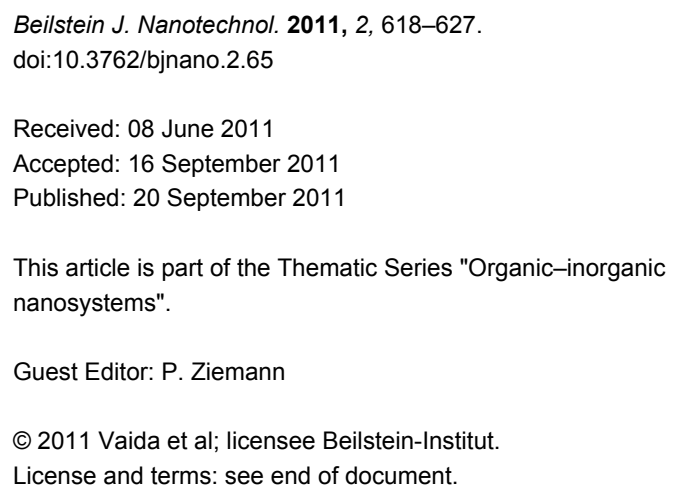

\begin{abstract}
The photodissociation of small organic molecules, namely methyl iodide, methyl bromide, and methyl chloride, adsorbed on a metal surface was investigated in real time by means of femtosecond-laser pump-probe mass spectrometry. A weakly interacting gold surface was employed as substrate because the intact adsorption of the methyl halide molecules was desired prior to photoexcitation. The gold surface was prepared as an ultrathin film on $\mathrm{Mo}(100)$. The molecular adsorption behavior was characterized by coverage dependent temperature programmed desorption spectroscopy. Submonolayer preparations were irradiated with UV light of $266 \mathrm{~nm}$ wavelength and the subsequently emerging methyl fragments were probed by photoionization and mass spectrometric detection. A strong dependence of the excitation mechanism and the light-induced dynamics on the type of molecule was observed. Possible photoexcitation mechanisms included direct photoexcitation to the dissociative A-band of the methyl halide molecules as well as the attachment of surface-emitted electrons with transient negative ion formation and subsequent molecular fragmentation. Both reaction pathways were energetically possible in the case of methyl iodide, yet, no methyl fragments were observed. As a likely explanation, the rapid quenching of the excited states prior to fragmentation is proposed. This quenching mechanism could be prevented by modification of the gold surface through pre-adsorption of iodine atoms. In contrast, the A-band of methyl bromide was not energetically directly accessible through $266 \mathrm{~nm}$ excitation. Nevertheless, the one-photon-induced dissociation was observed in the case of methyl bromide. This was interpreted as being due to a considerable energetic down-shift of the electronic A-band states of methyl bromide by about $1.5 \mathrm{eV}$ through interaction with the gold substrate. Finally, for methyl chloride no photofragmentation could be detected at all.
\end{abstract}




\section{Introduction}

The understanding of the mechanisms involved in the lightinduced excitation and fragmentation of organic molecules on metal substrates is of great importance in several research areas and applications connected to surface chemistry and catalysis. Photostability, photooxidation, and photocatalysis are important concepts in this respect that attract considerable interest in the fields of nanotechnology and surface engineering [1,2]. The present investigation focuses on fundamental mechanistic aspects associated with the interaction of small organic molecules with metal surfaces. For this purpose, ultrafast, timeresolved laser spectroscopy was applied to provide insight into light-induced molecular fragmentation on surfaces on the timescale of nuclear motion. The system under investigation was a nanoscale organic-inorganic layer structure composed of an organic overlayer adsorbed on a weakly interacting ultrathin gold film on a Mo(100) single crystal substrate. Methyl halide molecules are simple pseudo-diatomic photochemical model systems, which have been studied in great detail in the gas phase (see, e.g., [3-7]) as well on several metallic and nonmetallic solid substrates (see, e.g., [8-14]). The adsorption of methyl iodide on a gold surface has been previously investigated $[9,11]$. However, nothing has been reported so far about the adsorption of methyl bromide or methyl chloride on gold. Also, no ultrafast time-resolved laser investigations of methyl halide molecules on metal substrates have been performed so far. Only recently, the femtosecond (fs)-laser time-resolved photodissociation of methyl iodide and methyl bromide on oxide-supported gold nanoparticles was investigated [15-17]. The gold films employed in the presented experiment for the investigation of photoinduced reaction dynamics of methyl halide molecules on metallic supports were grown on $\mathrm{Mo}(100)$.

The central questions of the present investigation are concerned with the dependence of the photoexcitation and the subsequent photodissociation dynamics on the electronic structure of the organic adsorbates and, even more importantly, on the interaction with the substrate surface. Furthermore, the obtained results provide insight into fundamental issues of the ultrafast reaction dynamics of molecules on metallic surfaces and the influence of organic-molecule-inorganic-substrate interactions on the molecular photoreaction dynamics.

\section{Results and Discussion}

In the following, the results of the molecular adsorption studies and the investigations of the photodissociation dynamics are presented for the three molecular-adsorbate systems investigated. The characterization of the ultrathin gold films on $\mathrm{Mo}(100)$ that have been employed as a substrate in the present study is detailed in Supporting Information File 1.

\section{Adsorption of methyl halide molecules on $\mathrm{Au} / \mathrm{Mo}(100)$ Methyl iodide}

Figure 1a shows temperature-programmed desorption (TPD) spectra recorded after dosing different amounts of $\mathrm{CD}_{3} \mathrm{I}$ molecules at $90 \mathrm{~K}$ onto a $10 \mathrm{ML}$ gold film grown on $\mathrm{Mo}(100)$. Similar to the TPD investigations of methyl iodide on $\mathrm{Au}(100)$ [11] and on $\mathrm{Au}(111)$ [9] surfaces that have been reported in the literature, we found that most of the first layer desorbs without fragmentation. At submonolayer coverage just one desorption peak, which shifts to lower temperature with increasing coverage, appears in the TPD spectra. A similar desorption feature has been observed for $\mathrm{CH}_{3} \mathrm{I}[10,18]$ and $\mathrm{CH}_{3} \mathrm{Br}$ [12] on $\mathrm{MgO}, \mathrm{CH}_{3} \mathrm{Br}$ on $\mathrm{LiF}$ [19], and $\mathrm{CH}_{3} \mathrm{Cl}$ on $\mathrm{Pd}(100)$ [20], as well as for $\mathrm{CH}_{3} \mathrm{Cl}, \mathrm{CH}_{3} \mathrm{Br}$ and $\mathrm{CH}_{3} \mathrm{I}$ on $\mathrm{GaAs}(110)$ [21,22], and the coverage dependence is attributed to the adsorbate-adsorbate repulsion that results from the interaction between the static dipole moments of adsorbed molecules. Due to this lateral repulsion between the adsorbate molecules, the activation energy for desorption decreases with increasing coverage and, hence, the desorption temperature decreases. The completion of the first monolayer of $\mathrm{CD}_{3} \mathrm{I}$ molecules appears for doses just below $4.75 \mathrm{~L}$, in agreement with the previous investigations on $\mathrm{Au}(100)$ [11]. The peak below $140 \mathrm{~K}$ in Figure 1a is due to the multilayer desorption. Higher coverages were not investigated in this experiment.

About $4 \%$ of the $\mathrm{CD}_{3} \mathrm{I}$ molecules of the first layer dissociate and produce ethane. The inset in Figure 1a shows the evolution of the ethane signal in the temperature-programmed reaction of $\mathrm{CD}_{3}$ I molecules on the $10 \mathrm{ML} \mathrm{Au}$ film on $\mathrm{Mo}(100)$. The ethane signal starts just below $300 \mathrm{~K}$, extends up to $400 \mathrm{~K}$ and presents a maximum at $350 \mathrm{~K}$. Based on similar results for $\mathrm{Au}(100)$ [11] and $\mathrm{Au}(111)$ [9], the ethane formation is thought to be a consequence of methyl iodide dissociation followed by coupling between the methyl radicals. Since the temperature at which ethane appears is higher than that for the ethane molecular desorption (below $100 \mathrm{~K}$ ), it was concluded that the ethane formation is the rate-determining step as opposed to the desorption [11]. Furthermore, it can be assumed that the methyl iodide molecules involved in the thermal reaction are adsorbed on defect sites and dissociate close to the ethane-appearance temperature $(300 \mathrm{~K})[11]$. The remaining iodine atoms resulting from dissociation should desorb from the surface as atoms at temperatures higher than $650 \mathrm{~K}$ [23] (not investigated here). The intensity of the ethane signal saturates at a $\mathrm{CD}_{3} \mathrm{I}$ coverage corresponding to an exposure of about $0.75 \mathrm{~L}$ in agreement with the previous investigation of Yang et al. [11]. No other thermal reaction products were detected. 


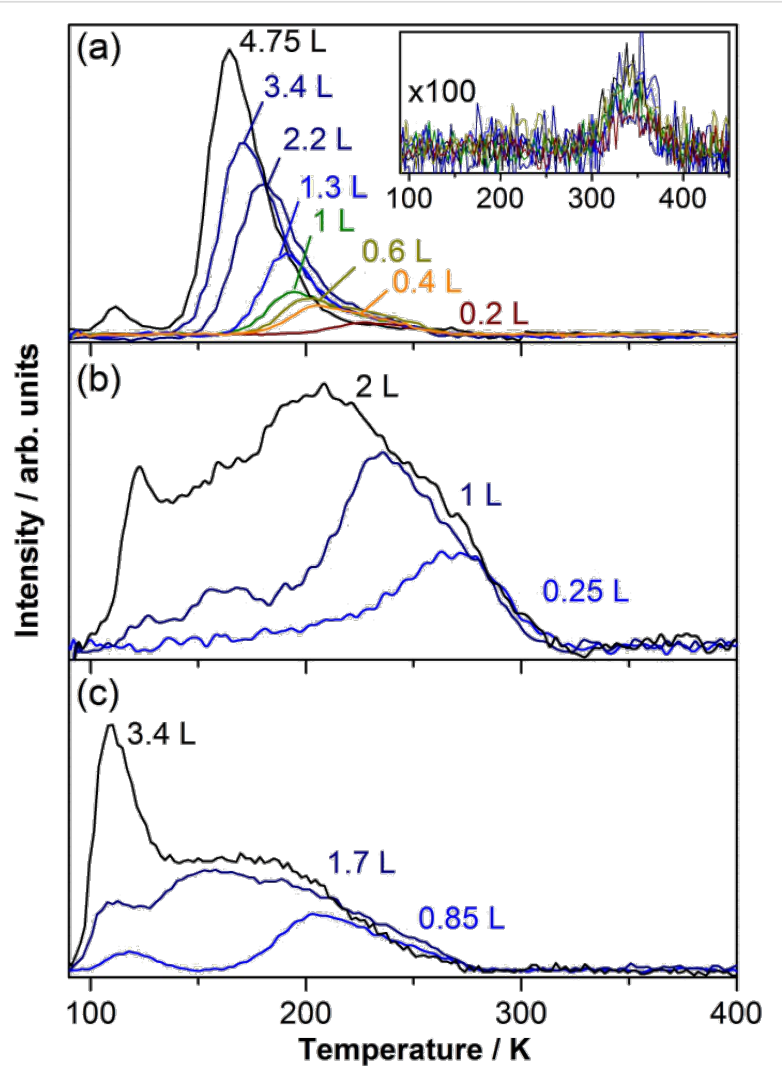

Figure 1: Temperature-programmed desorption/reaction spectra showing the molecular desorption of: (a) $\mathrm{CD}_{3} \mathrm{l}$, (b) $\mathrm{CH}_{3} \mathrm{Br}$ and (c) $\mathrm{CH}_{3} \mathrm{Cl}$ from a $10 \mathrm{ML}$ Au film on $\mathrm{Mo}(100)$. The numbers indicated next to the spectra represent the methyl halide exposure in units of Langmuir. The inset displays the $\mathrm{C}_{2} \mathrm{D}_{6}$ signal evolution. The $\mathrm{C}_{2} \mathrm{D}_{6}$ signal intensity has been multiplied by a factor of 100 . All spectra were obtained with a heating rate of $2 \mathrm{~K} / \mathrm{s}$.

\section{Methyl bromide}

The adsorption behavior of methyl bromide on a gold surface was also investigated by means of TPD spectroscopy, and the results are displayed in Figure 1b. Methyl bromide generally desorbed at higher temperatures from the gold substrate as compared to methyl iodide. For an exposure of $0.25 \mathrm{~L}$ the $\mathrm{CH}_{3} \mathrm{Br}$ desorption began at around $150 \mathrm{~K}$ and extended to $310 \mathrm{~K}$, with an intensity maximum at about $275 \mathrm{~K}$. For an exposure of $1 \mathrm{~L} \mathrm{CH}_{3} \mathrm{Br}$, a decrease of the maximum desorption temperature to about $235 \mathrm{~K}$ was observed. Additionally, a new desorption feature appeared below $200 \mathrm{~K}$. When $2 \mathrm{~L}$ of $\mathrm{CH}_{3} \mathrm{Br}$ were dosed onto the $\mathrm{Au}$ film, a distinct desorption peak at $120 \mathrm{~K}$ was observed separate from the main desorption peak as observed at lower coverages, with the maximum now shifted to $205 \mathrm{~K}$. No investigations of the adsorption of methyl bromide molecules on a gold surface have been reported so far in the literature. The interpretation of the features displayed in Figure $1 \mathrm{~b}$ is therefore based on TPD experiments with methyl halide molecules adsorbed on different substrates, which have been reported in the literature (see above). The desorption peak above $170 \mathrm{~K}$ is assigned to the molecular desorption of $\mathrm{CH}_{3} \mathrm{Br}$ molecules from the gold surface. Its shift to lower temperature with increasing adsorbate coverage is attributed also to a repulsive desorption that is caused by the interaction between the static dipole moments of the adsorbed molecules. A similar desorption characteristic was observed for submonolayer coverages of $\mathrm{CH}_{3} \mathrm{Br}$ on $\mathrm{Ru}(001)$ [13]. The distinct peak at $120 \mathrm{~K}$ is assigned to the onset of the $\mathrm{CH}_{3} \mathrm{Br}$ multilayer desorption, which was observed to start at an exposure of 3.4 $\mathrm{L}$ on $\mathrm{Ru}(001)$ [13]. In contrast to methyl iodide adsorbed on a gold surface, no thermally induced reaction products of $\mathrm{CH}_{3} \mathrm{Br}$, such as methane or ethane, were detected. As well, no evidence for methyl bromide dissociation subsequent to adsorption on the Au substrate was found.

\section{Methyl chloride}

Similar to the case of methyl bromide, no desorption studies of methyl chloride on a gold surface have been reported so far. Our results are depicted in Figure 1c. Already at 0.85 L exposure two desorption features were observed. The high-temperature peak shifts to lower temperatures with increasing coverage, indicating again repulsive adsorbate-adsorbate interactions. Interestingly, already at $0.85 \mathrm{~L}$ exposure a low-temperature desorption peak also emerges at around $110 \mathrm{~K}$. This peak might indicate early multilayer desorption, which would be in accordance with similar results of $\mathrm{CH}_{3} \mathrm{Cl}$ adsorbed on $\mathrm{Ru}(001)$ [13]. In this case the authors reported the onset of multilayer desorption for a methyl chloride exposure of 1.6 L. Also for methyl chloride no thermally induced reaction products were detected.

\section{Molecular photodissociation dynamics}

Molecular photoexcitation on solid surfaces is generally believed to proceed through one of the two following mechanisms:

1. Electron attachment leading to transient negative molecular ions, which in the case of the methyl halide molecules are unstable and subsequently decompose, or

2. direct photoexcitation of the adsorbed molecules to electronically excited states, which will determine the following photoreaction dynamics. For the methyl halide molecules the first optically accessible states belong to the dissociative A-band.

These two principally possible photoexcitation scenarios are schematically illustrated in Figure 2 for the methyl halide molecules adsorbed on a metal surface. For methyl iodide both reaction pathways are energetically possible with the absorption of one pump-laser photon of $266 \mathrm{~nm}$ wavelength. For methyl bromide and methyl chloride the A-band absorption maximum is 
6.2 and $7.3 \mathrm{eV}$, respectively, above the electronic ground state of the free molecules [3] and thus not accessible through onephoton excitation at $266 \mathrm{~nm}(4.7 \mathrm{eV})$.

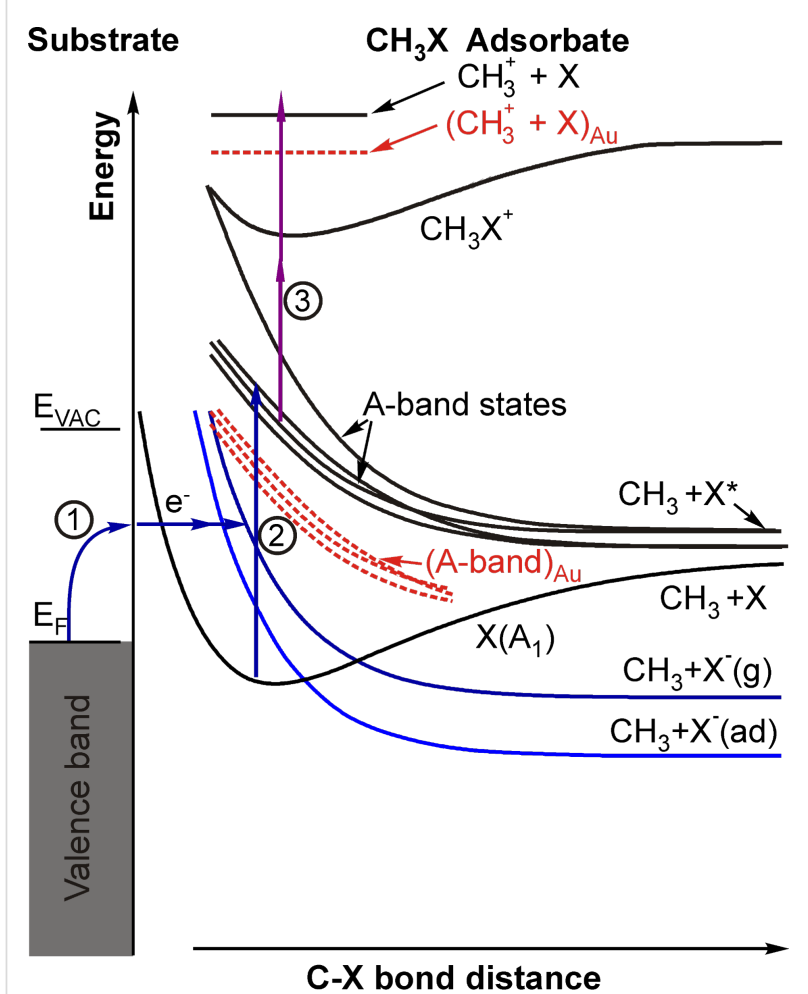

Figure 2: Schematic potential energy diagram for $\mathrm{CH}_{3} \mathrm{X}(\mathrm{X}=\mathrm{I}, \mathrm{Br}, \mathrm{Cl})$ molecules adsorbed on a metal surface. The shape of the potentials and the general idea have been adapted from data on $\mathrm{CH}_{3} \mathrm{Br}$ in $[7,24-$ 27]. The numbers of the excitation and detection mechanisms refer to the discussion in the text. The electronic levels that are proposed to be involved in the excitation and detection mechanism on the gold surface are indicated by the dashed red lines.

\section{Methyl iodide}

Methyl iodide photodissociation on gold: $\mathrm{CD}_{3} \mathrm{I}$ was adsorbed at submonolayer coverage on a $10 \mathrm{ML} \mathrm{Au}$ film on $\mathrm{Mo}(100)$ and irradiated with fs-laser pulses of $266 \mathrm{~nm}$ wavelength (pump beam, $80 \mathrm{fs}$, p-polarized, $1-2 \mathrm{~mW} / \mathrm{cm}^{2}$ ). For the subsequent fragment ionization a probe laser beam with a wavelength of $333 \mathrm{~nm}$ (80 fs, p-polarized, $600 \mathrm{~mW} / \mathrm{cm}^{2}$ ) was employed. However, neither photodissociation products nor the parent molecule were detected, independent on the pump-probe delay time. Similar results were reported by White and coworkers for methyl iodide adsorbed on Pt(111) [28-31]. In their work, methyl iodide molecules that were adsorbed on the metal surface were exposed to the full spectrum of an $\mathrm{Hg}$ arc lamp. The photodissociation and the desorption of the molecules from the surface was subsequently monitored by means of X-ray photoemission spectroscopy. White and coworkers reported that only $10 \%$ of the first $\mathrm{CH}_{3} \mathrm{I}$ layer adsorbed on the $\mathrm{Pt}(111)$ sub- strate dissociated when the sample was irradiated for $120 \mathrm{~min}$ with a $100 \mathrm{~W} \mathrm{Hg}$ arc lamp [29]. In contrast, a facile cleavage of the second layer was observed. According to vibrational spectroscopy investigations, the methyl iodide molecules adsorb on a Pt(111) surface with the halogen atom bound to the surface and with the $\mathrm{C}-\mathrm{I}$ axis considerably tilted away from the surface normal [32]. On $\mathrm{Au}(100)$ an adsorption geometry with the $\mathrm{C}-\mathrm{I}$ axis almost parallel to the surface plane is even expected for $\mathrm{CH}_{3} \mathrm{I}$ at submonolayer coverages [11]. Under these circumstances, the ground state of the $\mathrm{CH}_{3} \mathrm{I}$ molecule is only slightly perturbed from the gas phase. In contrast, the excited state is strongly bound to the metal surface, which facilitates the recapturing of the ground state before the $\mathrm{C}-\mathrm{I}$ bond stretches considerably. As a consequence, the molecule will almost instantaneously relax back to the ground state after excitation, and the molecular dissociation will be quenched [29]. Also on an $\mathrm{Ag}(111)$ surface the methyl iodide molecules adsorbed at monolayer coverage are photodissociated at a slower rate compared to those adsorbed at multilayer coverages, which also indicates a substantial quenching of the photodissociation when the molecules are in contact with the metal substrate $[33,34]$. In contrast to $\mathrm{CH}_{3} \mathrm{I}$, however, the photodissociation of the first monolayer of $\mathrm{CH}_{3} \mathrm{Br}$ and $\mathrm{CH}_{3} \mathrm{Cl}$ is easily promoted on the $\mathrm{Pt}(111)$ surface through UV irradiation [24,31,35,36].

Trapping of iodine atoms at the surface subsequent to $C D_{3} I$ photodissociation on gold: Figure 3 displays the time evolution of the $\mathrm{CD}_{3}{ }^{+}$signal during continuous admission of $\mathrm{CD}_{3} \mathrm{I}$ to a $10 \mathrm{ML} \mathrm{Au}$ film on Mo(100). The surface temperature was held at $120 \mathrm{~K}$ to ensure a maximum $\mathrm{CD}_{3} \mathrm{I}$ coverage of just about one monolayer (Figure 1a and [11]). In the beginning (period A in Figure 3), the surface was continuously irradiated by the pumpand probe-laser beams. An increase of the $\mathrm{CD}_{3}{ }^{+}$signal intensity was observed, starting after a few tens of seconds. The saturation of the $\mathrm{CD}_{3}{ }^{+}$signal appeared close to $2000 \mathrm{~s}$. The $\mathrm{CD}_{3}{ }^{+}$ signal up to $2000 \mathrm{~s}$ approximates to an exponential rise function. The obtained time constant is $\tau_{\mathrm{A}}=410 \pm 20 \mathrm{~s}$. After $2000 \mathrm{~s}$ (period B in Figure 3), the $\mathrm{CD}_{3} \mathrm{I}$ admission was stopped, but the surface was further irradiated by the laser beams. The $\mathrm{CD}_{3}{ }^{+}$signal immediately started to decrease. This decay is best fitted by a second-order exponential decay function. The time constants of the fast and slow decaying parts are $\tau_{\mathrm{B} 1}=55 \pm 5 \mathrm{~s}$ and $\tau_{\mathrm{B} 2}=300 \pm 100 \mathrm{~s}$, respectively. After $3000 \mathrm{~s}$ the $\mathrm{CD}_{3} \mathrm{I}$ gas admission was restarted (period $\mathrm{C}$ in Figure 3) and the $\mathrm{CD}_{3}{ }^{+}$ signal exhibited an abrupt increase. The best fit to this signal with an exponential rise function gives a time constant of $\tau_{\mathrm{C}}=$ $75 \pm 22 \mathrm{~s}$.

The initial rise of the $\mathrm{CD}_{3}{ }^{+}$signal in Figure 3 (period A) cannot be attributed to the continuous accumulation of $\mathrm{CD}_{3} \mathrm{I}$ molecules onto the surface, since the saturation of the monolayer is 


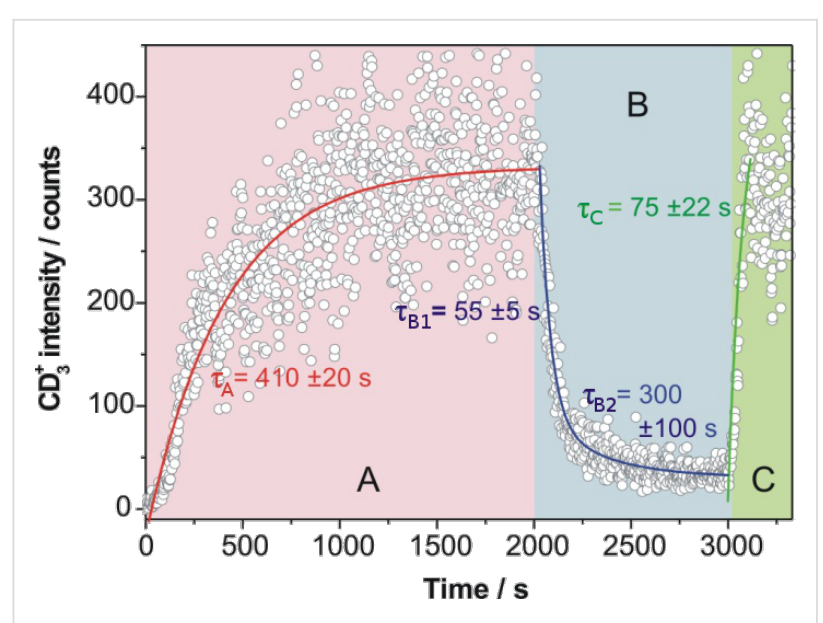

Figure 3: Time evolution of the integral $\mathrm{CD}_{3}{ }^{+}$intensity (open circles) during the continuous admission of $\mathrm{CD}_{3} \mathrm{l}$ to a $10 \mathrm{ML}$ Au film on $\mathrm{Mo}(100)$. The surface temperature was $120 \mathrm{~K}$. At $2000 \mathrm{~s}$ the gas admission was stopped for $1000 \mathrm{~s}$. The solid lines represent the best fits to the different parts of the measured data (A, B and C) with exponential growth and decay functions, as appropriate (see text for more details). Pump pulse: $266 \mathrm{~nm}, 2 \mathrm{~mW} / \mathrm{cm}^{2}$; probe pulse: $333 \mathrm{~nm}$, $600 \mathrm{~mW} / \mathrm{cm}^{2}$; pump-probe delay time: $130 \mathrm{fs}$.

expected within less than $10 \mathrm{~s}$. Moreover, a subsequent irradiation of a new (but already covered with $\mathrm{CD}_{3} \mathrm{I}$ ) surface area, of the same sample, gave a similar exponential rise of the $\mathrm{CD}_{3}{ }^{+}$ signal. Therefore, it must be assumed that the result shown in Figure 3 indicates a change in the nature of the surface during laser irradiation. As discussed in the previous section, just a small amount of $\mathrm{C}-\mathrm{I}$ bond cleavage of $\mathrm{CH}_{3} \mathrm{I}$ at monolayer coverage on $\mathrm{Pt}(111)$ was observed after a long period (120 min) of irradiation with a $100 \mathrm{~W} \mathrm{Hg}$ arc lamp [29]. In the present experiment a much more intense light source, i.e., a fs-laser, was employed. Therefore, in our experiment the dissociation of the $\mathrm{CD}_{3} \mathrm{I}$ adsorbed at monolayer coverage on $\mathrm{Au}$ can be assumed to occur at a somewhat faster rate (on the time scale of tens of seconds in contrast to tens of minutes). According to the adsorption geometry and binding energy of methyl iodide molecules on the Au surface [11], we expect the trapping of the iodine atoms at the surface subsequent to $\mathrm{CD}_{3} \mathrm{I}$ photodissociation. Consequently, during the laser irradiation of the sample an iodine film (or a gold-iodine layer) might be formed between the $\mathrm{Au}$ surface and the subsequently adsorbed $\mathrm{CD}_{3} \mathrm{I}$ molecules. On this iodine film, the photodissociation of the $\mathrm{CD}_{3} \mathrm{I}$ molecules should not be quenched anymore. The suggestion of the formation of an iodine layer, or at least an iodine containing gold layer, in the present experiment is supported by the investigations of White and coworkers, who observed that the $\mathrm{CH}_{3} \mathrm{I}$ photodissociation on a $\operatorname{Pt}(111)$ surface precovered with a monolayer of iodine atoms was not quenched either [37].

The rise time of the $\mathrm{CD}_{3}{ }^{+}$signal in Figure $3($ period A) should be related to the formation of the iodine layer. Once the sample is modified, i.e., the light-induced transformation $\mathrm{CD}_{3} \mathrm{I} / 10 \mathrm{ML}$ $\mathrm{Au} / \mathrm{Mo}(100) \rightarrow \mathrm{CD}_{3} \mathrm{I} / \mathrm{I} / 10 \mathrm{ML} \mathrm{Au} / \mathrm{Mo}(100)$ is completed, the laser can induce the dissociation and fragment desorption of an significant fraction of the $\mathrm{CH}_{3} \mathrm{I}$ molecules that are adsorbed on the iodine layer. The dissociated and desorbed amount of $\mathrm{CD}_{3} \mathrm{I}$ is immediately restored owing to the continuous admission, and a stable methyl desorption signal is established at the end of period A in Figure 3. In period B of Figure 3, the fast decaying part is attributed to the dissociation of the uppermost $\mathrm{CD}_{3} \mathrm{I}$ molecules that were weakly adsorbed on the iodine layer. The slowly decaying part in period $\mathrm{B}$ could be attributed to the dissociation of strongly bound $\mathrm{CD}_{3} \mathrm{I}$ molecules, which were possibly surrounded by iodine atoms. Towards the end of period $B$ in Figure 3 it can be expected that the sample surface consisted mostly of iodine atoms adsorbed on the gold film on Mo(100). The considerably faster rise of the methyl signal in period $\mathrm{C}$ of Figure 3, when the gas admission was restarted, compared to the one obtained in the beginning of the experiment (see period A in Figure 3), supports the assumption that a change of the surface composition after laser irradiation during continuous methyl iodide admission had occurred. The $\mathrm{CD}_{3}{ }^{+}$ signal in period $\mathrm{C}$ is attributed to the dissociation of $\mathrm{CD}_{3} \mathrm{I}$ molecules adsorbed on the new iodide film that was formed during the previous laser irradiation. The fast rise of the $\mathrm{CD}_{3}{ }^{+}$signal then reflects the time needed to saturate this iodine film surface with $\mathrm{CD}_{3} \mathrm{I}$ molecules. The maximum $\mathrm{CD}_{3}{ }^{+}$signal intensities reached in both periods $\mathrm{B}$ and $\mathrm{C}$ coincide. The exact values of the time constants presented in Figure 3 depend of course strongly on the laser intensity. In particular, the rise time in period A can be considerably extended at reduced laser intensity.

In Figure 4 laser desorption mass spectra recorded from the sample surface employed in the previous experiment (Figure 3) after $3500 \mathrm{~s}$ are shown. At a surface temperature of $150 \mathrm{~K}$ (Figure 4a), signals corresponding to atomic and molecular iodine are detected separate from the methyl mass peak. At $150 \mathrm{~K}$ the $\mathrm{CD}_{3} \mathrm{I}$ coverage is below one monolayer (Figure 1a) and therefore, iodine atoms and molecules can also be desorbed by laser irradiation from the iodine layer on the gold surface, which also supports the assumption that iodine atom fragments have been previously trapped on the gold surface.

In contrast, at $100 \mathrm{~K}$ surface temperature multilayer coverages of $\mathrm{CD}_{3} \mathrm{I}$ are possible. The mass spectrum in Figure $4 \mathrm{~b}$ was obtained at this surface temperature and confirms that, under these multilayer conditions, the atomic and molecular iodine desorption from the iodine layer on the gold surface is suppressed because the iodine layer is completely covered by $\mathrm{CD}_{3} \mathrm{I}$. In addition, when the sample was held at $100 \mathrm{~K}$ the methyl peak intensity was about 35 times higher than that at 


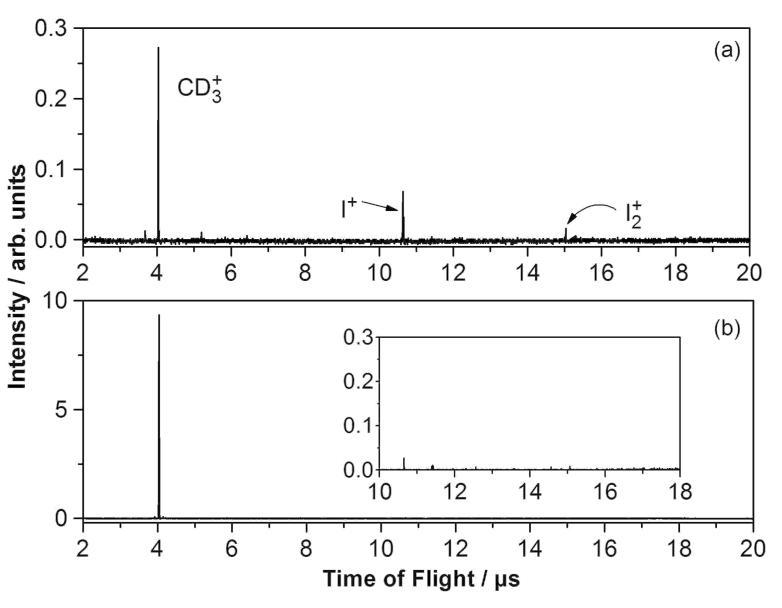

Figure 4: Mass spectra recorded at (a) $150 \mathrm{~K}$ and (b) $100 \mathrm{~K}$ from the same sample surface as in Figure 3 period C, after $3500 \mathrm{~s}$. The inset presents a zoom-in to the mass spectrum (b). During the recording of the mass spectra, $\mathrm{CD}_{3}$ I was continuously dosed onto the surface. Pump pulse: $266 \mathrm{~nm}, 2 \mathrm{~mW} / \mathrm{cm}^{2}$; probe pulse: $333 \mathrm{~nm}, 600 \mathrm{~mW} / \mathrm{cm}^{2}$; pump-probe delay time: $130 \mathrm{fs}$.

$150 \mathrm{~K}$ owing to the $\mathrm{CD}_{3} \mathrm{I}$ multilayer formation (note that at the chosen delay time of $130 \mathrm{fs}$ no iodine atoms or $\mathrm{I}_{2}$ molecules resulting from molecular $\mathrm{CH}_{3} \mathrm{I}$ photodissociation were detected with the employed probe laser beam [38]; the detected I-atoms and $\mathrm{I}_{2}$ molecules in the mass spectrum must therefore originate from the iodine layer on the gold surface). On the modified gold surface $(\mathrm{I} / \mathrm{Au} / \mathrm{Mo}(100))$ it was then possible to record the fs photodissociation dynamics of $\mathrm{CD}_{3} \mathrm{I}$ by monitoring the transient methyl cation signal intensity as a function of the pump-probe delay. The result is shown in Figure 5. The $\mathrm{CD}_{3}{ }^{+}$ transient signal consists of a peak structure with a maximum at $50 \mathrm{fs}$. The interpretation of this transient is based on earlier experiments with methyl iodide on an insulating magnesia surface and on the power dependences of the pump and the probe laser, which support a single-photon excitation followed by a two-photon ionization $[18,38,39]$.

Dissociative electron attachment according to excitation mechanism (1) in Figure 2 might be possible. In this way transient $\mathrm{CH}_{3} \mathrm{I}^{-}$ions would be generated, which would subsequently decompose. However, the formation of methyl cations would in this case involve a transition from the anion, via the neutral, to the cation. Of course, the exact locations of the respective potential energy surfaces are not known, but owing to the steep slope of the potentials at short distances (Figure 2) it is likely that this would require a three-photon transition, which is not in accordance with our observed two-photon ionization probe process. Therefore, it is assumed instead that one single photon of $266 \mathrm{~nm}$ excited the adsorbed methyl iodide molecule to the A-band (excitation mechanism (2) in Figure 2). The peak structure is then attributed to the dynamics of the dissociating

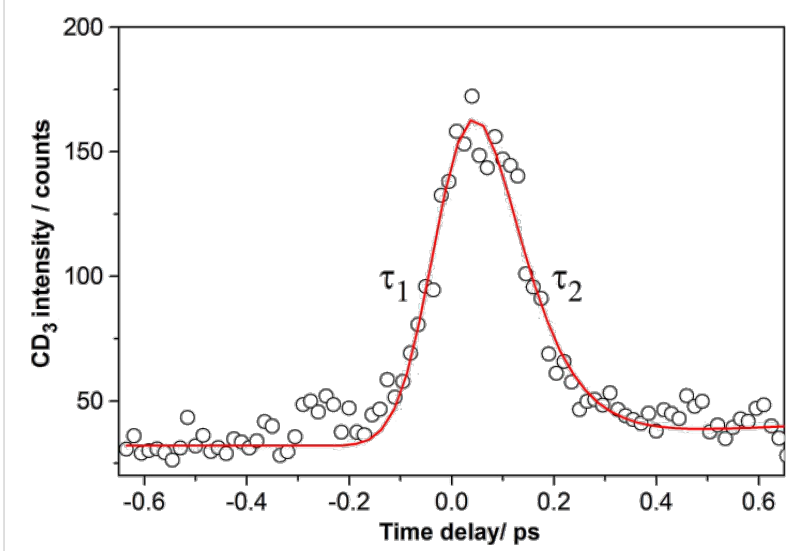

Figure 5: Femtosecond photodissociation reaction of multilayer methyl

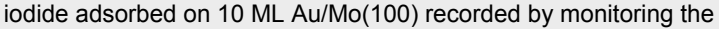
transient methyl cation signal intensity as a function of the pump-probe delay time (pump: $266 \mathrm{~nm}, 2 \mathrm{~mW} / \mathrm{cm}^{2}$ and probe: $333 \mathrm{~nm}$ $60 \mathrm{~mW} / \mathrm{cm}^{2}$ ). The solid line is the best fit of an exponential "rise and decay" model to the experimental data, yielding the indicated time constants $\mathrm{T}_{1}$ and $\mathrm{T}_{2}$.

excited transition state of methyl iodide in the A-band, which can be directly ionized with the highest cross section after $50 \mathrm{fs}$ by two photons of the probe pulse at $333 \mathrm{~nm}$ wavelength (excitation mechanism (3) in Figure 2). Subsequent rapid decomposition of the excited methyl iodide cation is proposed to lead to the observed methyl fragment signal. Fitting the experimental data with an exponential "rise and decay" model (convoluted with the laser cross correlation function) yielded the time constants of $\tau_{1}=60 \pm 10 \mathrm{fs}$ and $\tau_{2}=70 \pm 10$ fs for the rise and decay of the peak structure, respectively.

\section{Methyl bromide}

In contrast to methyl iodide molecules adsorbed at submonolayer coverage on the gold surface, which did not photodissociate, methyl bromide adsorbed on the same substrate at submonolayer coverage was easily photodissociated. Figure $6 \mathrm{a}$ displays a mass spectrum recorded from submonolayer (0.25 ML) $\mathrm{CH}_{3} \mathrm{Br}$ adsorbed on $10 \mathrm{ML} \mathrm{Au} / \mathrm{Mo}(100)$. The spectrum was recorded at $90 \mathrm{~K}$. The pump and probe wavelengths were $266 \mathrm{~nm}$ and $333 \mathrm{~nm}$, respectively. The pump-probe delay time was fixed to $140 \mathrm{fs}$. As can be seen, the only observed photoreaction product was $\mathrm{CH}_{3}{ }^{+}$. Mass spectra recorded under different experimental conditions, i.e., different pump-probe delay times, laser intensities, coverages, and temperatures, did not lead to the detection of other reaction products.

The time evolution of this methyl cation signal is shown in Figure 6b. Similar to the real-time photodissociation of $\mathrm{CD}_{3} \mathrm{I}$ molecules on $\mathrm{I} / \mathrm{Au} / \mathrm{Mo}(100)$, which was discussed above, the $\mathrm{CH}_{3}{ }^{+}$transient signal in Figure $6 \mathrm{~b}$ exhibits a peak structure. The signal starts at $0 \mathrm{fs}$ and no $\mathrm{CH}_{3}{ }^{+}$transient signal was detected 

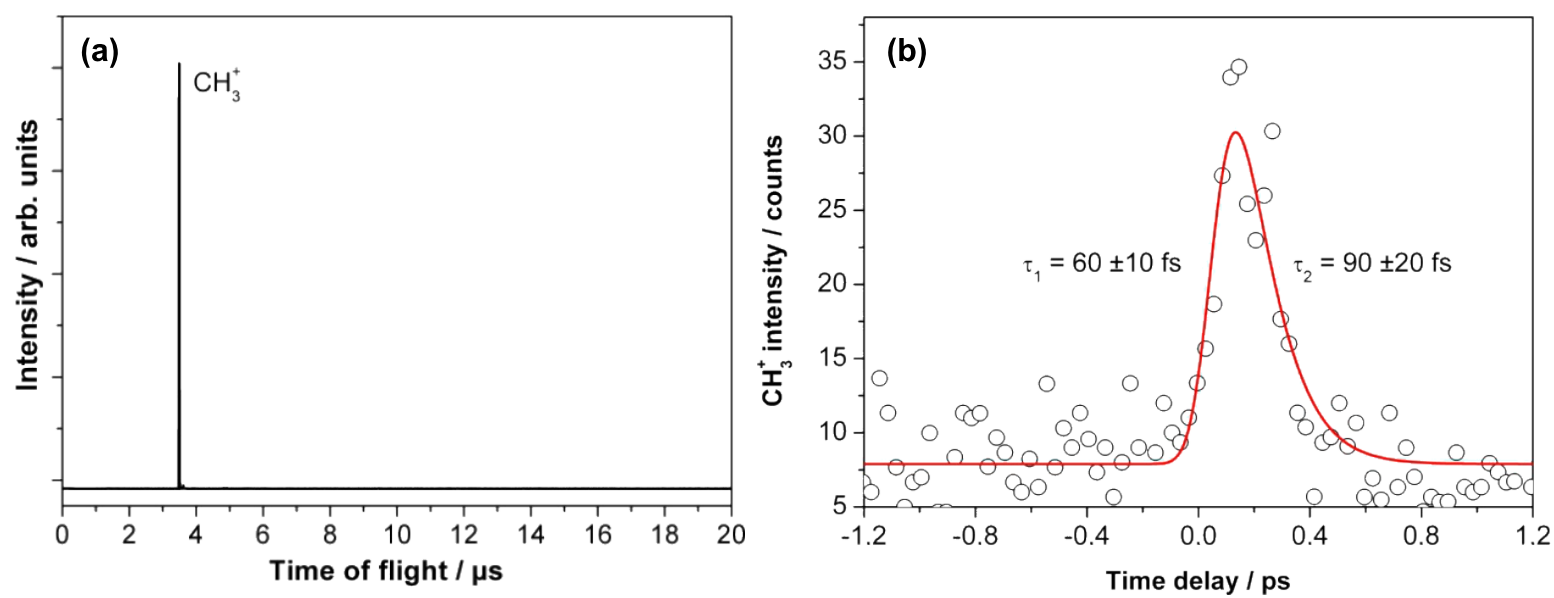

Figure 6: (a) Time-of-flight mass spectrum obtained from $0.25 \mathrm{ML}$ methyl bromide adsorbed on a $10 \mathrm{ML}$ Au film on Mo(100) at 140 fs pump-probe delay time. (b) Transient fs-photodissociation dynamics of $\mathrm{CH}_{3} \mathrm{Br}$ molecules adsorbed on $\mathrm{Au}(100) / \mathrm{Mo}(100)$ recorded by monitoring the $\mathrm{CH}_{3}{ }^{+}$signal as a function of the pump-probe time delay. The surface temperature was $150 \mathrm{~K}$. The solid line is the best fit of an exponential "rise and decay"-model to the experimental data, yielding the indicated time constants $\mathrm{T}_{1}$ and $\mathrm{T}_{2}$. For the shown transient, four single transients were averaged to improve the signal-to-noise ratio. The transient was obtained with $2 \mathrm{~mW} / \mathrm{cm}^{2}$ pump $(266 \mathrm{~nm})$ and $200 \mathrm{~mW} / \mathrm{cm}^{2}$ probe $(333 \mathrm{~nm})$ laser power.

for reaction times longer than $600 \mathrm{fs}$. The measured data were also fitted with an exponential "rise and decay" model. The determined rise and decay time constants were $\tau_{1}=60 \pm 10 \mathrm{fs}$ and $\tau_{2}=90 \pm 20 \mathrm{fs}$, respectively. The maximum of the peak structure was located at $140 \pm 20 \mathrm{fs}$. The error of $\pm 20 \mathrm{fs}$, in determining the maximum intensity, was derived from several transients recorded under similar conditions, i.e., similar substrate preparation, molecular coverage, and laser parameters. The other errors in determining the time constants were acquired directly from the fitting procedure.

Laser power dependence measurements indicated that the fundamental mechanism of the $\mathrm{CH}_{3} \mathrm{Br}$ photodissociation on the gold film is similar to that of methyl iodide on $\mathrm{I} / \mathrm{Au} / \mathrm{Mo}(100)$. The pump and probe power dependences of the $\mathrm{CH}_{3}{ }^{+}$signal intensity at $140 \mathrm{fs}$ pump-probe delay time are depicted in Figure 7 in a double-logarithmic representation. The slope of the graphs is an indication of the number of photons involved in the respective processes. From Figure 7 it can be seen that one pump photon was needed to excite the adsorbed $\mathrm{CH}_{3} \mathrm{Br}$ molecules. Therefore, the electron attachment mechanism might be possible, however, the two-photon probe power dependence renders this option again unlikely because rather three photons of $333 \mathrm{~nm}$ would be expected to be required to excite $\mathrm{CH}_{3} \mathrm{Br}^{-}$ to $\mathrm{CH}_{3} \mathrm{Br}^{+}$. The A-band of the free methyl bromide molecule has its maximum absorption cross section at around $6.2 \mathrm{eV}$ [3]. The observation that $\mathrm{CH}_{3} \mathrm{Br}$ adsorbed on $\mathrm{Au}$ can be excited by means of a single photon with a central wavelength of $266 \mathrm{~nm}$ $(4.7 \mathrm{eV})$ to a dissociative state, which is most likely the A-band, thus strongly indicates that the gold substrate induces a red-shift of the $\mathrm{CH}_{3} \mathrm{Br}$ A-band of about $1.5 \mathrm{eV}$. This energetic down- shift of the A-band states due to the interaction of the molecules with the gold surface is schematically indicated by the red dashed lines in Figure 2. Similar results were reported in the literature for $\mathrm{CH}_{3} \mathrm{Br}$ adsorbed on $\mathrm{Ag}(111)$ [34]. Figure $7 \mathrm{~b}$ displays the quadratic power dependence measured for the probe laser beam, which confirms that two probe photons are most likely required to generate the ionized methyl fragments.

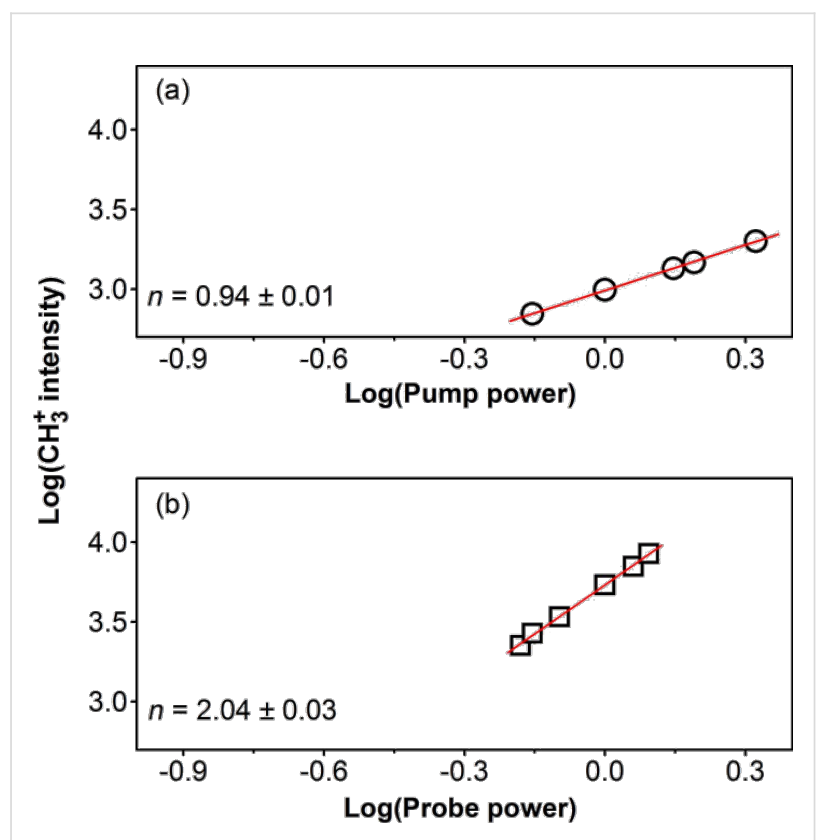

Figure 7: Intensity of the $\mathrm{CH}_{3}{ }^{+}$signal as a function of (a) pump power and (b) probe power. Both measurements (a) and (b) were performed for a pump-probe delay time of $140 \mathrm{fs}$. The straight lines represent linear fits to the experimental data yielding the indicated slopes $n$. 
Therefore, it is assumed that the excited adsorbate molecules were ionized by two nonresonant photons of $333 \mathrm{~nm}$ wavelength, and the ionized excited transition state decomposed yielding the $\mathrm{CH}_{3}{ }^{+}$fragment.

The maximum intensity of the $\mathrm{CH}_{3}{ }^{+}$transient peak obtained from the $\mathrm{CH}_{3} \mathrm{Br}$ photodissociation on gold is located at $140 \mathrm{fs}$ (Figure 6b), whereas the transient peak of the $\mathrm{CD}_{3}{ }^{+}$signal resulting from $\mathrm{CD}_{3} \mathrm{I}$ photodissociation on $\mathrm{I} / \mathrm{Au} / \mathrm{Mo}(100)$ was located at $50 \mathrm{fs}$ with slightly different time constants for the rise and the decay of the signal. This is a clear indication of the different interaction of $\mathrm{CH}_{3} \mathrm{Br}$ with $\mathrm{Au} / \mathrm{Mo}(100)$ compared to that of $\mathrm{CD}_{3} \mathrm{I}$ with $\mathrm{I} / \mathrm{Au} / \mathrm{Mo}(100)$. Thus, if the molecules dissociate by direct photoexcitation through the A state (which is proposed for methyl iodide and bromide), then these data represent intramolecular dynamics of the weakly perturbed molecule sitting on the Au surface, i.e., the dynamics in the transitionstate region of photodissociation, which is intimately influenced by the detailed interaction with the surface. Clearly, further insight from first principles simulations on these systems would be highly desirable to complement the experimental data.

\section{Methyl chloride}

No light-induced formation of fragments was observed in the case of methyl chloride. This is most likely due to the fact that the A-band of $\mathrm{CH}_{3} \mathrm{Cl}$ with an absorption maximum at $7.3 \mathrm{eV}$ above the electronic ground state of the free molecule [3] cannot be energetically lowered enough to become accessible to the $4.7 \mathrm{eV}$ photons of the $266 \mathrm{~nm}$ pump laser beam.

\section{Conclusion}

The present investigation demonstrates that time resolved pump-probe fs-laser time-of-flight mass spectrometry is able to probe the photodissociation dynamics of organic molecules on metallic substrates. The observed molecular dynamics varies strongly for the three investigated methyl halide molecules and reflects the different electronic structure of the molecules as well as the interaction with the gold substrate surface. The dissociation of methyl iodide on gold after UV irradiation was found to be quenched. In contrast, a modification of the gold substrate by slowly emerging iodine fragments was observed, which inhibited the quenching mechanism and enabled the measurement of transient methyl fragment signals. In the case of methyl bromide one-photon excitation was found to lead to the decomposition of the molecules on the gold surface. This was interpreted as an indication for a considerable red-shift of the A-band excitation of methyl bromide due to the interaction with the substrate. The alternative mechanism of dissociative electron attachment was found to be unlikely to be responsible for the observed dynamics of both molecules. Methyl chloride did not yield any detectable photofragments.

\section{Experimental}

The experiments were performed in an ultrahigh vacuum (UHV) chamber equipped with standard tools for surface preparation and characterization $[15,18,40]$. Prior to deposition of the gold film, the surface was cleaned by heating the Mo(100) crystal to $2000 \mathrm{~K}$ by means of electron bombardment. Subsequently, the surface temperature was ramped down to $1000 \mathrm{~K}$. In order to avoid the surface contamination, the Mo crystal was held at $1000 \mathrm{~K}$ by resistive heating until the background pressure restored $\left(<5 \times 10^{-10} \mathrm{mbar}\right)$. Subsequently the surface was cooled down to the deposition temperature of $400 \mathrm{~K}$. The gold evaporator was initially degassed and subsequently gave stable deposition rates over extended periods of time. In order to ensure the constant evaporation rate, prior to each deposition, the Au oven was preheated for $15 \mathrm{~min}$. Subsequently, the substrate was positioned $10 \mathrm{~mm}$ away from the gold source and the support was held at $400 \mathrm{~K}$. The gold evaporation was performed at normal incidence. The maximum background pressure in the UHV chamber reached throughout the gold evaporation process was less than $2 \times 10^{-9}$ mbar. Deuterated methyl iodide was employed in the present study, but test measurements with $\mathrm{CH}_{3} \mathrm{I}$ yielded identical results. $\mathrm{CD}_{3} \mathrm{I}, \mathrm{CH}_{3} \mathrm{Br}$, and $\mathrm{CH}_{3} \mathrm{Cl}$ (all from Sigma-Aldrich, $>99.5 \%$, additionally purified by several freeze-pump-thaw cycles) were dosed onto the gold substrate at $90 \mathrm{~K}$ by means of an UHV compatible pulsed valve that was connected to a stainless steel tube ending close to the surface.

The fs pump (266 nm, third harmonic of fundamental, $80 \mathrm{fs}$, $1 \mathrm{~mW} / \mathrm{cm}^{2}$ average power, p-polarized) and probe $(333 \mathrm{~nm}$ central wavelength, tuned by an OPA, $80 \mathrm{fs}, 600 \mathrm{~mW} / \mathrm{cm}^{2}$ average power, p-polarized) were generated by a commercial amplified $1 \mathrm{kHz}$ Ti:sapphire laser system (Spectra Physics Spitfire). The time zero in the experiments was determined in situ by monitoring the integral pump-probe time-dependent twophoton electron emission signal from the molybdenum surface.

Mass measurements were carried out on a homebuilt time-offlight mass spectrometer $[18,39]$. The grounded $\mathrm{Au} / \mathrm{Mo}(100)$ substrate served as the repeller electrode of a Wiley-McLarentype acceleration lens arrangement [41]. The pump and probe laser beams collinearly irradiated the surface at an angle of $45^{\circ}$. Reaction products and intermediates that were ionized by the probe laser pulse were immediately removed from the surface and directed into the time-of-flight mass spectrometer by the static electric field between the substrate surface and the first acceleration electrode of the mass spectrometer. The ions pass a field free drift tube with different velocities according to their mass-to-charge ratio and are finally detected by a multichannel plate amplifier arrangement as a function of their flight time. To obtain the transient evolution of the product ion mass signals, 
the mass peaks were averaged over 2500 laser pulses for a fixed pump-probe delay time. The initial coverage was subsequently restored by admitting an identical amount of compound to the surface with the pulsed valve. Subsequently, the procedure was repeated for a new pump-probe delay time. Several of the thus obtained transients were averaged to yield the shown data.

\section{Supporting Information}

Supporting information features the description of the characterization of the gold ultrathin films on $\operatorname{Mo}(100)$.

\section{Supporting Information File 1}

Characterization of ultrathin gold films on $\mathrm{Mo}(100)$. [http://www.beilstein-journals.org/bjnano/content/ supplementary/2190-4286-2-65-S1.pdf]

\section{Acknowledgements}

The work presented was supported by the Deutsche Forschungsgemeinschaft (SFB 569) and by the Fonds der Chemischen Industrie. MEV acknowledges a fellowship from the DAAD.

\section{References}

1. Pickett, J. E.; Moore, J. E. In Polymer Durability; Clough, R. L.; Billingham, N. C.; Gillen, K. T., Eds.; ACS Publications: Washington, DC, 1996; Vol. 249, p 287. doi:10.1021/ba-1996-0249.ch019

2. Esswein, A. J.; Nocera, D. G. Chem. Rev. 2007, 107, 4022. doi:10.1021/cr050193e

3. Felps, W. S.; Rupnik, K.; McGlynn, S. P. J. Phys. Chem. 1991, 95, 639. doi:10.1021/j100155a028

4. Alekseyev, A. B.; Liebermann, H.-P.; Buenker, R. J. J. Chem. Phys. 2007, 126, 234103. doi:10.1063/1.2736696

5. Alekseyev, A. B.; Liebermann, H.-P.; Buenker, R. J.; Yurchenko, S. N. J. Chem. Phys. 2007, 126, 234102. doi:10.1063/1.2736695

6. de Nalda, R.; Durá, J.; Garcia-Vela, A.; Izquierdo, J. G.; González-Vázquez, J.; Bañares, L. J. Chem. Phys. 2008, 128, 244309. doi:10.1063/1.2943198

7. Blanchet, V.; Samartzis, P. C.; Wodtke, A. M. J. Chem. Phys. 2009, 130, 034304. doi:10.1063/1.3058730

8. Kutzner, J.; Lindeke, G.; Welge, K. H.; Feldmann, D. J. Chem. Phys. 1989, 90, 548. doi:10.1063/1.456506

9. Paul, A. M.; Bent, B. E. J. Catal. 1994, 147, 264. doi:10.1006/jcat.1994.1137

10. Holbert, V. P.; Garrett, S. J.; Bruns, J. C.; Stair, P. C.; Weitz, E. Surf. Sci. 1994, 314, 107. doi:10.1016/0039-6028(94)90217-8

11. Yang, M. X.; Jo, S. K.; Paul, A.; Avila, L.; Bent, B. E.; Nishikida, K. Surf. Sci. 1995, 325, 102. doi:10.1016/0039-6028(94)00722-5

12. Garrett, S. J.; Heyd, D. V.; Polanyi, J. C. J. Chem. Phys. 1997, 106, 7847. doi:10.1063/1.473743

13. Livneh, T.; Asscher, M. Langmuir 1998, 14, 1348. doi:10.1021/la970712b

14. Osgood, R. Chem. Rev. 2006, 106, 4379. doi:10.1021/cr050175x
15. Vaida, M. E.; Bernhardt, T. M. Eur. Phys. J. D 2009, 52, 119. doi:10.1140/epjd/e2009-00064-2

16. Vaida, M. E.; Gleitsmann, T.; Tchitnga, R.; Bernhardt, T. M. Phys. Status Solidi B 2010, 247, 1139. doi:10.1002/pssb.200945518

17. Vaida, M. E.; Bernhardt, T. M. In AIP Conference Proceedings, Vol. 1387, PHYSICS CONFERENCE TIM-10, Timisoara, Romania, Nov 25-27, 2010; Bunoiu, M.; Malaescu, I., Eds.; American Institute of Physics: Melville, NY, 2011.

18. Vaida, M. E.; Hindelang, P. E.; Bernhardt, T. M. J. Chem. Phys. 2008, 129, 011105. doi:10.1063/1.2953578

19. Garrett, S. J.; Heyd, D. V.; Polanyi, J. C. J. Chem. Phys. 1997, 106, 7834. doi:10.1063/1.473742

20. Berko, A.; Erley, W.; Sander, D. J. Chem. Phys. 1990, 93, 8300. doi:10.1063/1.459312

21. Lasky, P. J.; Lu, P. H.; Yang, M. X.; Osgood, R. M., Jr.; Bent, B. E.; Stevens, P. A. Surf. Sci. 1995, 336, 140. doi:10.1016/0039-6028(95)00493-9

22. Lu, P. H.; Lasky, P. J.; Yang, Q. Y.; Osgood, R. M., Jr. Chem. Phys. 1996, 205, 143. doi:10.1016/0301-0104(95)00377-0

23. Neumann, A.; Christmann, K.; Solomun, T. Surf. Sci. 1993, 287-288, 593. doi:10.1016/0039-6028(93)91034-M

24. Ukraintsev, V. A.; Long, T. J.; Gowl, T.; Harrison, I. J. Chem. Phys. 1992, 96, 9114. doi:10.1021/j100202a009

25. Camillone, N., III; Khan, K. A.; Yarmoff, J. A.; Osgood, R. M., Jr. Phys. Rev. Lett. 2001, 87, 056101. doi:10.1103/PhysRevLett.87.056101

26. Escure, C.; Leininger, T.; Lepetit, B. J. Chem. Phys. 2009, 130, 244306. doi:10.1063/1.3152865

27. Escure, C.; Leininger, T.; Lepetit, B. J. Chem. Phys. 2009, 130, 244305. doi:10.1063/1.3154140

28. Costello, S. A.; Roop, B.; Liu, Z. M.; White, J. M. J. Phys. Chem. 1988, 92, 1019. doi:10.1021/j100316a006

29. Liu, Z. M.; Akhter, S.; Roop, B.; White, J. M. J. Am. Chem. Soc. 1988, 110, 8708. doi:10.1021/ja00234a029

30. Liu, Z. M.; Costello, S. A.; Roop, B.; Coon, S. R.; Akhter, S.; White, J. M. J. Phys. Chem. 1989, 93, 7681. doi:10.1021/j100359a030

31. Roop, B.; Lloyd, K. G.; Costello, S. A.; Campion, A.; White, J. M. J. Chem. Phys. 1989, 91, 5103. doi:10.1063/1.457602

32. Henderson, M. A.; Mitchell, G. E.; White, J. M. Surf. Sci. 1987, 184, L325. doi:10.1016/S0039-6028(87)80258-3

33. Domen, K.; Chuang, T. J. J. Chem. Phys. 1989, 90, 3332. doi:10.1063/1.455887

34. Zhou, X.-L.; White, J. M. Surf. Sci. 1991, 241, 270. doi:10.1016/0039-6028(91)90087-9

35. Jo, S. K.; Zhu, X.-Y.; Lennon, D.; White, J. M. Surf. Sci. 1991, 241, 231. doi:10.1016/0039-6028(91)90084-6

36. Ukraintsev, V. A.; Long, T. J.; Harrison, I. J. Chem. Phys. 1992, 96, 3957. doi:10.1063/1.461898

37. Zhou, X.-L.; White, J. M. In Laser spectroscopy and photochemistry on metal surfaces; Dai, H.-L.; Ho, W., Eds.; Advanced Series in Physical Chemistry, Vol. 5; World Scientific: Singapore, 1995.

38. Vaida, M. E.; Bernhardt, T. M. ChemPhysChem 2010, 11, 804. doi:10.1002/cphc.200900920

39. Vaida, M. E.; Bernhardt, T. M. Rev. Sci. Instrum. 2010, 81, 104103. doi:10.1063/1.3488098

40. Gleitsmann, T.; Vaida, M. E.; Bernhardt, T. M.; Bonačić-Koutecký, V.; Bürgel, C.; Kuznetsov, A. E.; Mitrić, R. Eur. Phys. J. D 2007, 45, 477. doi:10.1140/epjd/e2007-00257-7

41. Wiley, W. C.; McLaren, I. H. Rev. Sci. Instrum. 1955, 26, 1150. doi:10.1063/1.1715212 


\section{License and Terms}

This is an Open Access article under the terms of the Creative Commons Attribution License

(http://creativecommons.org/licenses/by/2.0), which permits unrestricted use, distribution, and reproduction in any medium, provided the original work is properly cited.

The license is subject to the Beilstein Journal of Nanotechnology terms and conditions:

(http://www.beilstein-journals.org/bjnano)

The definitive version of this article is the electronic one which can be found at:

doi:10.3762/bjnano.2.65 